NOTAS

\title{
JUAN GARCÍA PONCE Y EL DISCURSO DE LA TRANSGRESIÓN
}

Juan Antonio Rosado*

Generalmente, las representaciones estéticas en la narrativa de Juan García Ponce (Mérida, 1932) son eróticas, hay un erotismo ubicuo, pero también un elemento que subyace bajo el erotismo o la pornografía: la transgresión de un orden moral y social. Al contrario de lo que ocurría en Oriente, donde hay tratados eróticos sin otro fin que el de mostrar el modo de producir diversidad y placer en la relación sexual, nuestra civilización judeocristiana ha puesto la marca del pecado en el placer que implica el sexo disociado de la reproducción. Dios manda a los humanos a reproducirse, así como en el Evangelio Cristo seca una higuera porque ésta no da frutos, a pesar de que no era época de higos.

En una nota de La parte maldita, Georges Bataille alude a la expresión -eminentemente judeocristia-

* Facultad de Filosofía y Letras, UNAM. na- de pecado 'carnal' para expresar el vínculo entre la sexualidad y la muerte, que devora la carne. La postura, que le confiere gran importancia a la producción, contrasta con la literatura oriental, donde el amor -sin importar que sea improductivo- vence a la muerte. En la India -donde no hubo dioses prometeicos ni héroes fármacos vencidos por la fatalidad- el erotismo como placer transgrede el orden del trabajo, pero no el moral ni religioso. Comparemos la actitud de la Biblia, donde el Cantar de los cantares aparece casi por milagro, con estos versos de un texto sagrado hindú anterior al Antiguo Testamento: "tres veces por día tú me penetrabas con tu falo / y me colmabas hasta cuando yo no lo deseaba”, en los que la mujer expresa el placer, la pérdida de energía, sin explicitar ningún fin utilitario, como podría ser la fecundidad. En Las lágrimas de Eros, Bataille advierte que 
el placer inmediato que resulta del acto sexual -y no la procreación-fue el fin para los primeros hombres conscientes. Pienso, por ejemplo, en una tribu nómada de cazadores. Con seguridad obtenían el placer por el placer, pues el culto a la fertilidad se desarrolla en las sociedades agrícolas y sedentarias. En el Rig Veda, producto de una cultura originalmente nómada, hay muchos ejemplos de sexualidad explícita impregnada de la pureza e inocencia que implica la falta de culpa frente a algo tan natural como el sexo.

Cada cultura y persona poseen una actitud diferente frente a lo 'obsceno' y 'vergonzoso'. En el aspecto individual destaca, por ejemplo, la figura de Fray Luis de León, quien desde la cárcel aclara que la palabra hebrea zama, utilizada en el Cantar de los cantares, significa cabello, pero también "las vergüenzas de la mujer”, y de ninguna manera lo que puso San Jerónimo en su Vulgata. Arguye el fraile que "a los limpios y buenos, que no pervirtieron en nada el uso natural, todo lo natural les es limpio". En cuanto al aspecto cultural, para Alain Danielou, los templos hindúes están cubiertos de imágenes eróticas porque el hombre

debe ser puro, libre de inhibiciones antes de poder alcanzar los secretos del conocimiento. El sabio no teme el espectáculo del placer, sino que admira la floración y la belleza. [...] son los ambiciosos, los rapaces, los crueles, los acomplejados quienes temen a las manifestaciones de la sexualidad. El temor a lo sexual es siempre una manifestación de anti-espiritualidad.

Bataille, al referirse a los templos de la India, aclara que "fuera de los límites del cristianismo, el carácter religioso, el carácter sagrado del erotismo pudo aparecer a la luz del día, con el sentimiento sagrado dominando a la vergüenza”. Debe señalarse aquí que el elemento masculino predominó sobre todo en el norte del subcontinente, no así en el sur, donde la mujer fue fundamental en el tantrismo. Además, en los textos de arte erótica siempre se alude a una diversidad de posturas sexuales y se le da gran importancia al placer femenino. Para Vatsyayana, las mujeres deben conocer y estudiar el Kama Sutra. En cambio, en el mundo greco-latino, no obstante la libertad sexual, el varón, por ser activo, era siempre predominante. Artemidoro (s. II d.C.) incluso llegó a afirmar que lo 'natural' es hacer el amor frente a frente, con el hombre encima de la mujer, para poseerla y ser dueño de su cuerpo, de modo que ella -ser pasivo por naturaleza- se someta y obedezca: 
NOTAS

las demás posiciones sexuales son negativas.

En su Historia de la sexualidad, Michel Foucault cita a Artemidoro, según el cual las posiciones sexuales que se salen de lo 'normal' son “invenciones de la desmesura, de la intemperancia y de los excesos naturales a que lleva la embriaguez". Esta postura indica una carencia total de imaginación y refinamiento, y admite la inferioridad femenina. Aristóteles considera, en su Tratado de la generación de los animales, que "debemos entender la condición femenina como si fuera una deformidad." Para los griegos la civilización era primordialmente masculina y no se debe al azar el que, como dice Foucault, los griegos no hayan concebido un arte erótica, sino sólo reflexiones que apuntan "a la instauración de una técnica de vida".

En cambio, lo que implica el concepto de kama (placer sensual) era considerado en la antigua India como una de las etapas de la vida, junto con artha (adquisición de bienes materiales) y dharma (el deber, la obligación de cada quien para con su casta y sociedad). El objetivo del hinduista es moksha (liberar al alma de la transmigración), pero no excluye ni artha ni kama como etapas propias de la juventud.

Sin embargo, cuando el hombre inmerso en una cultura represiva se aparta de los fines meramente reproductivos para buscar el desgaste sexual por el placer mismo y, con ello, la franca anticoncepción, transgrede un precepto religioso, un orden moral. Para Bataille, el gasto improductivo se halla vinculado con lo sagrado. En García Ponce, lo que llamaré "discurso de la transgresión” está entretejido con representaciones implicadas en una concepción del mundo en cuyo vértice confluyen, por un lado, el carácter de desgaste de la energía vital sin ningún fin reproductivo y, por otro, el carácter religioso, sagrado, místico, ritual de una erótica inmersa en la intimidad de sus actuantes.

Pero la transgresión, entendida en sus aspectos más generales, no sólo puede percibirse desde un orden moral. Si el orden o la organización social -cualquiera que sea la cultura- surge gracias al trabajo, la estructura del tiempo en la civilización implica la obtención de los bienes que el trabajo produce en pro de un mejoramiento material (artha), gracias al cual será posible transgredir ese orden e incluir así el placer (kama) y su repetición ritual, cíclica dentro de la linealidad temporal acumulativa, de tal modo que dicha linealidad se rompe (es transgredida) cuando el rito penetra o irrumpe bajo cualquiera de sus formas: una fiesta, el 
tiempo para el placer, el sacrificio, el ocio...

El hombre, como dice Bataille, niega su animalidad en el trabajo, pero también niega el trabajo en el tiempo del ocio, aunque sin volver a la animalidad. En La parte maldita, el pensador francés afirma que la introducción del trabajo sustituyó a la intimidad, al deseo y a sus desenfrenos. Con el trabajo, lo que importa no es ya el presente, sino el "resultado posterior de las operaciones". Para Bataille-que juega con la expresión de Proust- el hombre, en sus mitos y ritos, está "a la búsqueda de una intimidad perdida”, que es donde aparece el erotismo y por ello también asegura que "tenemos la nostalgia de la continuidad perdida", porque tanto en el erotismo de los cuerpos como el de los corazones y el sagrado existe un sentimiento de continuidad.

Esta continuidad de los cuerpos en la intimidad es recuperada por García Ponce en el espacio literario: "Soy un autor de camas -afirma en una entrevista-, de lugares privados, de interiores, pero también de exteriores vistos como interiores..." Entonces la recuperación de esta intimidad, que sólo vive en el presente y dilapida el excedente de energía sin capitalizarlo, sin pensar en el futuro, es una transgresión del orden del trabajo como enajenación, que organiza la sociedad. El juego alternativo de la prohibición y de la transgresión es evidente en el erotismo, pues éste no existiría sin el respeto de los valores prohibidos ni tampoco habría pleno respeto si la ruptura erótica no fuera posible. Y si el espíritu religioso aparece como esa búsqueda por recuperar tal intimidad, los textos garciaponceanos, como los templos hindúes llenos de orgías, están inmersos en un tiempo sagrado donde el consumo de la energía sexual prevalece y el trabajo productivo irrumpe como excepción.

Los personajes principales de García Ponce poseen un excedente de energía física, de vitalidad, que entra en juego en la intimidad de la actividad sexual. Esta energía quiere prevalecer sobre el mundo del trabajo y de la 'realidad'; lo altera, lo transgrede. Si pensamos en la utilidad en el sentido que le confiere Bataille-como ventaja, mantenimiento y crecimiento- el gasto improductivo de vitalidad como rasgo de la autonomía o soberanía de los personajes del autor yucateco es inútil, pues sólo origina consumo, pérdida, desgaste de energía. Al oponerse a la realidad, al trabajo, la intimidad se ocupa sólo del presente. El trabajo de D en el cuento “El gato” es cómodo: un empleo que le quita unas cuantas horas diarias y por el que recibe lo suficiente para vivir. El 
NOTAS

protagonista de La invitación ni siquiera trabaja: vive con sus padres y sólo simpatiza con el movimiento estudiantil tras la represión de la que fue injustamente objeto.

La noción de consumo de energías, contraria a la deliberada preservación y producción, se hace constante en la narrativa de García Ponce. Por ejemplo, en el cuento "Rito", Liliana empieza a desnudar al invitado, bajo la contemplación de su esposo Arturo: "La escena parece corresponder más que nunca a una ceremonia en la que cada acto está previsto y parecería totalmente irreal si no fuera por su absoluto carácter violatorio que hace aparecer esa otra esfera en la que todo es posible.” Esa otra esfera es la transgresión. Como ocurre en las narraciones de Pierre Klossawski, se hace patente lo que este autor denomina las "Leyes de la hospitalidad” (donación de la mujer por el hombre a sus invitados).

Ahora bien, si es importante colocar en primera instancia el desgaste vital como elemento transgresor, en el autor yucateco la transgresión no sólo consiste en violar la norma social de productividad en el trabajo o en la actividad sexual. Hay otras evidentes y constantes transgresiones de las normas morales o sociales de conducta, que emanan de la primera y donde se viola no sólo el orden matrimonial sino también la misma relación de pareja. En Pasado presente, después de los sucesivos fracasos matrimoniales de Geneviève, esta mujer transgrede las normas morales al incluir a un tercero porque, de hecho, en el erotismo garciaponceano nunca hay tercero excluido. Además, los actores principales en la transgresión son las figuras femeninas. En este aspecto, García Ponce coincide con muchas jarchas mozárabes del siglo XI, donde la mujer adúltera incita a su amante a que la ayude a transgredir el orden matrimonial en que está inmersa porque no está su marido (el tercero excluido es la pareja legal; el erotismo sigue siendo de dos).

La postura sexual descrita en una de esas jarchas puede corresponder a una de las posiciones 'abiertas' del Kama Sutra, lo que implica una relación sexual ajena al deseo de procrear. Recordemos que en la Cábala, la primera mujer de Adán, Lilith, transgredió la postura sexual tradicional, en la que el aburrido Adán tenía que estar siempre arriba. Por ello Lilith fue arrojada del paraíso y convertida en demonio. Asimismo, la felación sería un ardid de Lilith para volver estéril el esperma.

En el Libro de buen amor, de Juan Ruiz, se advierte la influencia oriental en la figura de la Serrana, quien persigue el placer por el placer: acoge en su casa a cualquier hombre y 
le brinda comida, cama y sexo; este último, como paga del forastero por el hospedaje. La Iniciativa sexual es de la mujer y, como se sabe, en la cultura oriental no era mal visto que la mujer tuviera la iniciativa.

Las diferencias más notorias entre la concepción de la mujer en las jarchas, en el libro de Juan Ruiz y en García Ponce, es que, por un lado, las figuras femeninas en el autor yucateco suelen ser estimuladas o incitadas por la intervención de un personaje masculino, quien a su vez ha sido excitado o 'provocado' por la imagen femenina, por la visión de una mujer, la cual no sólo es el elemento primordial en la transgresión, sino también el personaje principal en prácticamente todas las obras del autor yucateco; y por otro, que en García Ponce no hay propiamente adulterio. Como ocurre en las novelas de Klossowski, el marido consiente que su mujer se acueste con otros, cosa que no sucede en las jarchas ni en cualquier otro texto medieval, como el Decamerón o los Cuentos de Canterbury, donde siempre hay adulterio.

La concepción plasmada por García Ponce se torna más interesante si tomamos en cuenta que la respuesta sexual de la mujer -multiorgásmica por naturaleza-fue en Occidente destruida o alterada por las restricciones sociales puritanas. Lo que suele llamarse 'revolución sexual' de los 60, para Masters y Johnson sería un renacimiento. Dice Masters que "En la comunidad agrícola, la igualdad sexual de la mujer nunca se había convertido en un problema [...] el sexo era algo que estaba previsto, que se estimaba, se disfrutaba... y se vivía."

Para determinar por qué se opera la transgresión es necesario reflexionar sobre el poder que indirectamente produce la violación de la norma. Advierte Klossowski: "La transgresión supone el orden existente, el mantenimiento aparente de las normas, en beneficio de una acumulación de energía que vuelve necesaria la transgresión”, y más adelante: “sólo obtiene su valor transgresivo de la permanencia de las normas", postura en la que coincide Bataille, que en El erotismo habla de la dialéctica prohibición-transgresión. Sólo un orden puede dar entrada a la posibilidad de transgresión. Las prohibiciones no dejan de imprimir un gran respeto a lo que defienden del acceso común. Es sintomático que la prohibición de naturaleza sexual haya dado un valor erótico al objeto, sea hombre o mujer. Por su parte, Michel Foucault sostiene que el crecimiento de las perversiones

es el producto real de la interferencia de un tipo de poder sobre 
NOTAS

el cuerpo y sus placeres. Es posible que Occidente no haya sido capaz de inventar placeres nuevos, y sin duda no descubrió vicios inéditos. Pero definió nuevas reglas para el juego de los poderes y los placeres: allí se dibujó el rostro fijo de las perversiones.

En la ‘introducción’ a El gato, García Ponce coloca a la representación como única regla del juego, un juego donde, como en Inmaculada o los placeres de la inocencia no hay juicios morales ni normas. Para su autor, esta omnipresencia lúdica coloca a su relato en el terreno de una transgresión: “que va más allá de cualquier norma establecida [...] y sabe que siendo los actores mismos, su realidad corporal, el único elemento indispensable al juego, tiene que dirigirse hacia los límites de ese cuerpo".

Pero en medio de esta neutralidad moral y artística ¿es transgresión la ‘transgresión' que va más allá de cualquier norma y juicio moral? No suele haber, en el arte de García Ponce, una conciencia de la existencia de normas. Entonces no hay, en éste y sólo en este sentido, transgresión. Sí la hay, en cambio, en el sentido de que existe un deseo de romper los límites del cuerpo, transgredirlos, ampliarlos para llegar a lo otro. La escritura no es ajena a esta transgre- sión mientras existan lectores que viven en una sociedad que sí acata normas. El discurso de la transgresión intenta romper los límites de la norma para constituirse como obra dentro de la sociedad.

Las novelas de García Ponce son herederas de un arte erótica que no implicaba la ciega aceptación de juicios morales y normas de conducta. Por ello habría que colocar esas normas, ese poder, en el ámbito cultural del lector (o de ciertos lectores) y en el de los personajes que las acatan; como el hermano de Inmaculada -representante de una cultura patriarcal y machista y narrador del cuento que le da título al libro en que apareció: "La noche”- quien al igual que su esposa, se escandaliza con la idea del divorcio, o Carola, en el cuento "Ninfeta", que asesina a su amante por considerarlo un pederasta que intentó seducir a su hija de doce años.

Ya en la obra de teatro El canto de los grillos, que se desarrolla en Mérida, uno de los personajes, la tía solterona Evenilde, es miembro de la Acción Católica, y Ana, su sobrina, llega a asumir el poder cultural que reprime al cuerpo: "En cualquier forma, hay ciertos límites que una muchacha decente no puede trasponer, nunca.” Ella misma llega a imponerle las reglas de conducta a Aída, su madre, que vive en el despiste y 
en la inocencia de la ingenuidad, y que por su carácter débil se deja arrastrar por el moralismo de su hermana Evenilde.

Los elementos transgresores de la moral tradicional, que configuran el discurso de la transgresión, le han costado a García Ponce epítetos como 'perverso', 'obsceno' o 'inmoral', todos con una carga axiológica alejada no sólo de muchos de sus personajes sino de la misma conciencia del narrador y, por lo tanto, extraños, parciales.

Siempre hay una especie de complicidad entre la ley y la violación de la ley. Lo importante ahora es determinar para qué o por qué se viola la ley. El estudiante Torless, en la novela de Robert Musil, no se introduce por los "callejones estrechos y retorcidos de la sensualidad" a causa de una perversión, "sino movido por una situación espiritual todavía desprovista de meta”. Es fundamental el apego espiritual que los personajes de García Ponce tienen hacia la abierta presencia femenina y hacia el fenómeno estético; ambas instancias están más allá de toda apreciación moral.

García Ponce parece coincidir con Musil cuando éste afirma: "El arte puede perfectamente elegir lo indecente y lo enfermo como punto de partida, pero a partir de ahí lo representado -no la representación, sino lo indecente y enfermo representadoya no es ni indecente ni enfermo." $\mathrm{El}$ arte no ocurre en ninguna parte y es en sí mismo amoral. "Yo no soy un escritor perverso -afirma el autor yucateco- yo me limito a contar. La perversidad la pone la moral particular de cada uno de mis lectores. Allá ellos con sus reglas", lo que me recuerda al llamado ‘voluntarismo' de San Agustín, interpretado por P.L. Ullman: "el mal está en el ojo que lee y no en el libro".

Con lo 'obsceno' ocurre algo similar. Bataille lo considera como una relación entre un sujeto y un objeto: "Esto es obsceno si tal persona lo ve y lo dice, no es exactamente un objeto, sino una relación entre un objeto y el espíritu de una persona.” Así, la prohibición de la desnudez aparece ya en el Génesis, cuando Adán y Eva se avergüenzan de ella, actitud que se contrapone a las representaciones de sexo y actos sexuales explícitos en otro texto sagrado: el ya aludido Rig Veda, donde nunca se mira ni al erotismo ni al sexo en sí como algo obsceno o inmoral. Al referirse a Inmaculada..., su autor escribe que la primera versión contenía mil páginas y que fue reduciéndola no sólo para que el discurso fuera más concentrado, sino también para que la novela fuera cada vez más amoral: no se trata de una novela ética porque, como aclara 
NOTAS

su autor, no es susceptible de ser observada de acuerdo al orden establecido y a las costumbres, que García Ponce no considera ni buenas ni malas, sino sólo costumbres: "mi intento era que la novela se despojara de sus propósitos morales hasta que no tuviera ninguno. Por ejemplo, ese manuscrito se iniciaba diciendo 'Desde un principio Inmaculada pareció haber sido elegida para el mal.' Y suprimí esa frase porque contenía un juicio moral que implicaba un bien. Y yo lo que quiero es que en Inmaculada no haya ni bien ni mal”. Seguramente, el autor colocó esa frase porque el bien, entendido como una quietud del espíritu que nos mueve a la santidad al separarnos de la vida, para García Ponce hace imposible el arte, pues el campo del arte es precisamente la vida, cosa que el santo no desea, no busca al estar ligado a lo trascendente. En la medida en que el concepto de transgresión del orden moral está vinculado a una determinación tecnológica marcada por un orden preestablecido en una conciencia axiológica emanada de un dualismo jerarquizado (bueno/malo, orden/desorden) es necesario que la sospecha del espectador de arte lo cuestione. La carencia de un centro ordenador que implica la apertura y pluralidad en la narrativa garciaponceana por sí misma admite lo que en la exterioridad al arte -en la vida- consideramos como 'transgresión' en tanto elemento de su desorden, al cual, para subsistir, debe transgredir su propia transgresión y así anularla al fijarla en la ordenada representación artística, que puede así convertirse en atractiva para el lector. Al hacer trascender la vida -que no es en sí misma ni buena ni mala, ni ordenada ni desordenada-, al fijarla, el arte debe ser amoral, pero ordenado -el orden narrativo, en el caso de la narración- y, por lo tanto, el concepto de "transgresión del orden moral" queda en entredicho dentro de los terrenos del espacio imaginado. En esto último insiste el escritor yucateco: "Hay que tener en cuenta el carácter amoral del arte. Yo no pretendo que las emociones producidas por conductas consideradas 'aberrantes' dentro de la moral tradicional sean legítimas dentro de esa moral.”

Para D. H. Lawrence, la obscenidad y la perversidad se dan cuando la mente desprecia o teme al cuerpo y el cuerpo odia la mente; es decir, cuando no hay equilibrio, armonía entre el sexo y el pensamiento. La perversión es precisamente esa carencia de equilibrio que puede bien existir en un venerable clérigo maestro de escuela que viola niñas a escondidas: la "perversión del puritanismo", la "perversión de la mente sucia”. Pero la perversión para García Ponce es 
también algo positivo, en el sentido de que el conocimiento nos pervierte, nos aleja de la inocencia, de la ingenuidad, pero a la vez nos puede hacer volver a la inocencia. Podemos entonces concluir que la 'perversidad’ de García Ponce sería en todo caso algo que también nos otorga un conocimiento y, por lo tanto, nos transforma: el Arte. En efecto, en su libro sobre Klossowski, Teología y pornografía..., utilizó los términos 'perverso' y 'perversidad' como aquello que aleja a la teología y a la sexualidad de sus objetivos. Como nunca llega a su fin porque "Dios ha muerto”, el razonamiento teológico se convierte en espectáculo, en un ‘juego perverso': la perversidad misma se convierte en fin dentro del espacio amoral de la obra artística.

El arte -afirma García Ponce- es rito, ceremonia. Tratar de crear ese rito, esa ceremonia, prostituir el lenguaje poniéndolo al servicio de la literatura, sería, en todo caso, mi perversidad. Pero los verdaderos perversos son los que observan ese rito, esa ceremonia a través de las palabras, en la literatura en mi caso. Su mirada, la de los espectadores, es una representación dentro de la representación que yo creo.
La trangresión existe precisamente porque hay miradas capaces de contemplarla o acaso de crearla mediante la contemplación. "La mirada -dice García Ponce- siempre es culpable: pone una intención y establece una distancia”, y también: “La culpa de la mirada sustituye a la inocencia de lo mirado.” Pero el artista nos hace cómplices y su obra, finalmente, "nos lleva a la inocencia", como quiere Eduardo, el profesorprotagonista de El libro.

En García Ponce, asimismo, se resalta el ímpetu repetitivo, cíclico, de exhibirse o de exhibir a otro a través de su objetivación. El placer de exhibirse es también el goce de anular la individualidad para objetivarse y ser de quienes miran. La fuerza subversiva permanece -invisible, latente, dispuesta a emerger y manifestarse en cualquier instante para alterar los códigos establecidos- entre las relaciones humanas que viven o se dejan vivir en la dura e inexorable cotidianidad, en ese presente puro y continuo a donde el pasado retorna. El mayor goce de dicha fuerza subversiva es experimentado en el espacio corporal y en los campos ajenos al trabajo y a todo lo que pueda implicar el principio de realidad. En La invitación, las evidentes resonancias paradisíacas de la íntima e ¿imaginaria? Beatrice se contraponen al infierno 
NOTAS

de la enfermedad de R., pero también a las infernales (¿reales?) sirenas y camiones militares de la ciudad.

En el arte de García Ponce la intimidad suele triunfar sobre el principio de realidad. La liberación de las necesidades instintivas que para la sociedad son prohibiciones crean un medio no represivo que se realiza en la intimidad, donde nunca hay una separación de la esfera instintiva y de la intelectual: placer y pensamiento se armonizan. El principio del placer se mantiene y nunca hay pugna con lo que Herbert Marcuse llama principio de actuación, que es el trabajo enajenado del hombre que sólo sirve como instrumento útil: el principio de la realidad establecida. Si en nuestra civilización hay 'progreso' gracias al sacrificio de la libido en el principio de realidad, en una literatura intimista la satisfacción de la libido se convierte en ritual. Pero si el subjetivismo y el psicologismo son ingredientes de las creaciones de García Ponce, las cuales nos hacen participar, intervenir en el desarrollo de cada personaje, en sus relaciones con lo otro y en la búsqueda del placer extático en esa otredad, es precisamente en el otro donde se pierde el sujeto. Este intimismo, por tanto, no debe ser entendido como la mera relación de pareja.

Masters y Johnson aclaran que el deseo de conservar la intimidad du- rante el acto sexual no es algo innato, sino el producto de un condicionamiento cultural. El sujeto se atiene a reglas tácitas que implican un pudor, aunque sólo sea simbólicamente. En la narrativa de García Ponce la intimidad sexual no deja de ser bajo techo o en la soledad, es decir, se halla determinada por una circunstancia particular, pero esta intimidad se abre considerablemente hasta aceptar una continuidad de prácticamente todas las combinaciones, excepto la homosexualidad masculina.

Pornografía o erotismo, la deliberada intención de excitar al lector y hacerlo penetrar en esa constante e implacable transgresión de las costumbres sexuales -lo que en el lenguaje de cierto moralismo suele llamarse ‘perversión'- y erotismo como violador de esos valores, se exhiben para ser admirados.

Pero García Ponce no pretende persuadir a su lector de que sea un perverso sino, en todo caso, hacerlo cómplice de los mundos que crea. La prueba es que no posee la necesidad de recurrir a los argumentos -sofísticos, según Klossowski- de Sade. Sofísticos porque los discursos del perverso en Sade no salen de la razón normativa. El persuadido debe rechazar las normas conscientemente, mientras que el cómplice acata la perversión sin necesidad de argumentos. En la medida en que la narrativa de 
García Ponce es intimista, se halla, en cierto sentido, liberada de esa generalidad normal a la que Sade invoca para que su contra-generalidad implícita se haga monstruosidad integral o prostitución universal.

Según el diccionario ‘perverso' es -en la acepción que nos interesael que corrompe las costumbres o el orden y estado habitual de las cosas. Pero los personajes de García Ponce, mediante la imaginación y la acción, crean y asumen su propio orden en la intimidad. Por tratarse de una obra de carácter intimista, el poder sobre el sexo no se transmite a partir de un discurso jurídico, pues éste es prácticamente inexistente al no regir el comportamiento sexual de los personajes, los cuales no atentan contra el orden social exterior porque se trata de una literatura disociada de los aspectos sociales. Por ejemplo, el doctor Ballester en Inmaculada..., aunque se considere un 'falso doctor' porque en realidad le interesan los enfermos como tales, no sólo tiene el cuidado de advertirle a Inmaculada que no comente dicha confesión, sino que también admite que 'cura' a algunos de sus pacientes. Además, jamás atenta contra el orden de su propia clínica. Al contrario, cuando Arnulfo -verdadero perverso y auténtico 'culpable'- introduce el desorden al 'contratar' a Inmaculada como prostituta para los locos, el Dr. Ballester no duda en despedirlo. En García Ponce jamás encontramos el asesinato ni la tortura, y en eso coincide con Henry Miller, quien afirma: "todo ese sadismo perverso me horroriza. Siempre he dicho que mi literatura es saludable porque es gozosa y natural. Nunca digo nada que la gente no diga y haga todo el tiempo”.

La disponibilidad de los personajes de García Ponce implica su propia voluntad de estar disponibles. Las pocas escenas de sadomasoquismo que hay en Inmaculada... se dan porque la protagonista descubre ese placer del poder como una parte interior, oculta en sí misma, y porque Rosenda y ella misma lo aceptan y lo asumen como adultos, sin 'aplastar' a nadie contra su voluntad. Después de que Inmaculada le pega a Rosenda, el pintor Ernesto Mercado les pega a las dos con el cinturón, pero les pide al final que hagan que Miguel y Tomás "no se den cuenta de los golpes", lo que implica una voluntad de no alterar el orden fuera de la propia intimidad y, sobre todo, la voluntad de tratar a las mujeres como individuos al propugnar por una complicidad mutua, ajena a la soledad del soberano personaje sadiano, quien, a decir de Bataille, no toma en cuenta a sus semejantes.

Tanto Blanchot como Bataille coinciden en que Sade niega al pró- 
NOTAS

jimo, hace su obra en la soledad, en la extrema discontinuidad con el mundo y el prójimo, y su mensaje es finalmente la insignificancia de los demás en la continuidad del crimen y de la crueldad, si bien es capaz, en uno de sus escritos ("Diálogo entre un sacerdote y un moribundo"), de formular una moral como ésta:

solamente la razón debe advertirnos que dañar a nuestros semejantes nunca puede hacernos dichosos; y nuestro corazón indicarnos que contribuir a la felicidad ajena es el más grande goce que la naturaleza nos haya acordado sobre la tierra. Toda la moral humana está contenida en esta sola frase: hacer tan felices a los demás como uno mismo desearía serlo y nunca causarles más daño del que uno mismo quisiera recibir.

En el discurso de García Ponce, ajeno a toda moral, la razón emerge para controlar y limitar la violencia: impone o implica así ciertas prohibiciones que hacen del juego algo placentero para todos, sin negar o victimar al otro por medio de la crueldad. En Pasado presente, por ejemplo, Virginia le tiene mucho miedo a los golpes de Abelardo y aprende a evitarlos, pero también aprende, gracias a Catalina, el placer del acto lesbiánico. En esta misma obra, Geneviève es manipulada "como si fuese un objeto", pero -y esto es lo importante- actuaba "de acuerdo no sólo con su placer, sino también con su temor al futuro".

En otras palabras, en García Ponce la razón no está puesta al servicio del horror sanguinario ni del uso del cuerpo con fines sádicos. Se trata, como afirma el moribundo del breve diálogo de Sade -personaje, por lo demás, excepcional en el corpus de la su obra- de producir la felicidad ajena y la propia. Para ello es necesario que la razón imponga ciertos límites. De hecho, en el terreno de la transgresión en general, Bataille aclara que ésta, al igual que la prohibición, está a menudo sujeta a reglas. Si García Ponce, como lo ha observado Armando Pereira, establece una relación con la literatura hecha de pasión y de lucidez -términos opuestos, ya que la pasión es irracional, mientras que la lucidez "es ese acto de conciencia que pone límites a la vehemencia del deseo"- este movimiento dialéctico se advierte también en sus personajes. En el interior de su obra narrativa, y por ello, paralela a la inocencia, se encuentra su negación dialéctica: desde que hay una lucidez, un raciocinio, un saber, la inocencia se vuelve relativa: "En verdad, nada era inocente, aunque tomara la forma de lo casual. Había una mal disimulada expecta- 
ción en cada uno de ellos. Ninguno de los gestos de Geneviève dejaba de acentuar su natural sensualidad.” Lo importante es que, como lo advierte Eduardo en El libro, de esa malicia se retorna a la inocencia del placer en sí: sin culpa alguna.

Prosiguiendo con Sade, el erotismo se sitúa en el dominio de los individuos, mientras que el sadismo lo hace en el de las personas cosificadas. Para que exista el sujeto obediente debe haber un sujeto que legisla; pero la obediencia y la disponibilidad, si bien se hallan vinculadas, no son lo mismo. La voluntad de estar dispuesto a obedecer implica la existencia de un individuo consciente de su voluntad y en una relación que puede ser de dependencia o de subordinación para con quien posee la voluntad de someter, o simplemente ser una relación de carácter lúdico, donde subsista la complicidad del mutuo acuerdo.

Pero se podrá argumentar que en Sade las acciones suelen también ocurrir en la intimidad y que, por lo tanto, no hay una real y efectiva alteración del orden social, por más pretensiones o persuasiones del 'filósofo infame'. Sin embargo, el hecho de que Sade adopte un discurso filosófico y moral y de que a veces invoque a la naturaleza para justificar las acciones crueles de los verdugos, implica que lo que pretende finalmente es convencer. Por otra parte, la comparación entre Sade y García Ponce podría establecerse en el orden erótico. Pero no se trata, como dice Nietzsche, de 'calumniar el desear' haciéndolo culpable. Afirma García Ponce que "la aspiración máxima de la moral, su meta, es la pureza absoluta. Y dentro de ella no existen los contrastes". Pero su aspiración -en sentido inverso- puede ser también la impureza absoluta, la prostitución universal $y$, entonces, tampoco acepta los contrastes. Si Sade es un moralista al revés es porque para él existen las prosperidades del vicio o los infortunios de la virtud y no, como en García Ponce, los placeres de la inocencia. Nuevamente, García Ponce coincide con Henry Miller, quien exclama: “¡Cuán afortunado soy de que no se me acuse de pervertido o degenerado sino simplemente de ser alguien que hace el sexo placentero e inocente!"

La dicotomía de Sade, que implica una conciencia moral y una transgresión consciente de las normas, no es explotada por García Ponce porque la propuesta del autor yucateco es -quiero insistir en ello- amoral, como el arte. Dice Gilberto en De anima: "La belleza, como Paloma, no tiene moral." Finalmente, tanto en Sade como en García Ponce encontramos un poder sobre el objeto erótico, pero en Sade este poder es 
ilimitado y va acompañado por una indiferencia a la suerte de la víctima; ya que ésta se vuelve insignificante, cosa que jamás ocurre en García Ponce, principalmente porque no hay verdugos que reclamen la obediencia absoluta de la víctima, es más, ni siquiera hay víctimas en el sentido sadiano. En la obra garciaponceana existe un reinicio de la fuerza vital, por ello no se da la aniquilación absoluta del objeto. Los personajes suelen elegir la vida, no como acto genésico sino placentero, conducente a la 'muerte', a la petite mort -extática, atemporal en el instante en que se da, pues es la anulación de la duración calculada- en el círculo vicioso enmarcado por el placer. No suele existir la elección de muerte implicada en la categoría batailleana de lo imposible como un vivir la libertad al borde de los límites porque los personajes del escritor yucateco no suelen estar abocados a un destino trágico: no hay Orestes propiamente dichos ni aberraciones ni crueldades ni desórdenes ilimitados y excesivos; "sólo está ávido de lo imposible quien se dibuja un destino trágico”, afirma Bataille.

Lo imposible, sin embargo, se manifiesta en la obra de García Ponce en tanto espacio literario y también como lo 'imposible sexual', como acto antigenésico (por ejemplo, en mujeres como Inmaculada), pero sin el aspecto terrible o sádico. Si admitimos con Bataille, que "El vicio podría concebirse como el arte de darse, de una manera más o menos maníaca, el sentimiento de la transgresión”, tanto Sade como García Ponce como Bataille en sus novelas, son autores 'viciosos', obsesivos: lo que cambia es el tipo de representación, las intenciones y, en definitiva, los matices y la concepción, ya que el discurso de la transgresión no es unívoco ni aparece en todos de la misma manera. En García Ponce más bien se dan las 'perversiones' que Herbert Marcuse califica como "compatibles con la normalidad en la alta civilización”, porque no atentan contra ella en tanto que no son formas inhumanas ni destructivas. Hay, en cambio, una reactivación de la sexualidad polimorfa: los personajes, aunque trabajen, adquieren, incluso en el trabajo, la satisfacción de sus necesidades individuales.

Ahora bien, si me parece impertinente comparar al escritor yucateco con el Marqués de Sade es, más que nada, porque en el primero aparece precisamente la amoral inocencia, elemento sobre el que ya se ha reflexionado desde la óptica freudiana sobre la sexualidad infantil, pero que a Octavio Paz le ha llamado la atención desde otra óptica. En Sade, la inocencia es un elemento negativo y pasivo (Justine es atracción para 
el libertino), mientras que en García Ponce la inocencia (por ejemplo, Inmaculada) juega un papel positivo y hasta activo. En Sade la filosofía es voluntad de desunir, transgredir, disgregar, violentar. La inocencia en sus personajes no existe porque ellos son conscientes de que están transgrediendo un orden jurídico y social al someter a sus víctimas, es decir, son culpables. Afirma Octavio Paz, refiriéndose a las obras de García Ponce, que la palabra inocencia, asociada a la sexualidad

no es realmente un término moral ni científico sino religioso: la inocencia es una plenitud de ser, del mismo modo que el pecado es una falta. La inocencia es abundancia, el pecado es carencia. Lawrence lo sabía perfectamente y, al hablar de sus novelas, en una carta a un amigo, le dice que todas ellas giran en torno al enigma de la sexualidad "y han sido escritas desde la profundidad de mi experiencia religiosa”.

En el arte erótico de García Ponce hay elementos religiosos -sin importar que sean o no heréticos desde la perspectiva cristiana- y una irrupción de lo sagrado y del misticismo. Todo ello contrasta con Sade, pues, como afirma Paz, en la figura del libertino "no hay unión entre religión y erotismo", si bien su actitud puede convertirse, por efecto de la pasión, en una religión al revés. En los 'monstruos’ de Sade no hay éxtasis, sino, en todo caso, frenesí, o un 'éxtasis' “del pensamiento en la representación del acto reiterado a 'sangre fría', éxtasis opuesto aquí a su análogo funcional: el orgasmo”. Como aclara Klossowski en un ensayo sobre Sade, tampoco existe la plenitud en el sentido que le confiere Paz, plenitud que, en cambio, se hace explícita aun en la solitaria Claudia, de La cabaña, que siente su cuerpo como una prolongación de su deseo y a la posibilidad de inocencia como elemento de ese deseo, aunque carezca de fin; que se reconoce "dueña de una limpia inocencia” y está llena de sí, aunque sin saber a dónde dirigir esa plenitud. La obra de García Ponce abunda en estos temas.

Por todo ello, cuando Roland Barthes asume que el dolor en Sade es nietzscheano, es decir, inocente -una desdicha inocente, un rechazo de la Falta- y compara la inocencia del enamorado con la de los héroes de Sade, no toma en cuenta el desplazamiento amoral de la pasión amorosa ni la excesiva moralidad transvaloradora que se opera en la conciencia del héroe sadiano, si entendemos por héroe el personaje que porta los valores explícita o implícitamente aceptados como positivos por el autor (no 
por el lector). Ni Sade, en sus escritos filosóficos, ni sus héroes, creen en el martirio cristiano como valor positivo. Tampoco García Ponce, pero en este escritor prevalece la amoralidad: las cosas representadas, ajenas generalmente a un discurso de la crueldad, simplemente son. Al final de La cabaña, Claudia no sabía "si hacía bien o mal”. En el libertinaje de Sade hay un conocimiento axiológico y una reflexión que lo invierte, hay un poder sin límites sobre el objeto, hay víctima y victimario, y es este último el héroe. Hay, por lo tanto, una relación destructiva. La única complicidad está entre los verdugos. En García Ponce, al contrario, es notoria la entrega, la complicidad con el otro, la alegre aceptación; por ello no existen víctimas ni victimarios en la intimidad, sino una voluntad de estar dispuesto porque todos son cómplices inocentes. Más que con Sade, García Ponce coincide con Henry Miller, para quien "el artista está obsesionado por el pensamiento de recrear el mundo, con el fin de restaurar la inocencia del hombre. Además sabe que el hombre sólo puede recuperar la inocencia si recobra su libertad”. Para el autor yucateco, “el arte es una búsqueda de la inocencia”, con la cual "no hay que enfrentar al mundo, sino que vivirlo”. El autor de Inmaculada... admite que la principal experiencia que le otorga la lectura de la poesía de Octavio Paz es que en la inocencia que nos muestra "reconocemos el principio sagrado de la vida y al hacerlo nuestras acciones recobran su sentido original, participan de la realidad de una manera natural”.

En su ensayo "Literatura y pornografía”, García Ponce anota un rasgo esencial de la conducta del libertino en Sade: su necesidad de convertir al otro en objeto de placer sin voluntad individual, "cuyo propósito es proporcionar placer y nada más”, y aclara que tanto en el libertino como en su víctima "sólo la degradación de la calidad como persona permite que el libertinaje se cumpla”. La diferencia con García Ponce es que en la poética vitalista de éste la desintegración del sujeto y la objetivación del otro tiene como fin y fundamento "ser sólo el placer que das y que te dan”, lo que implica una reciprocidad hedonista (o un hedonismo recíproco); mientras que, al decir de Bataille, el extremo del vicio es precisamente lo opuesto al placer. Es cierto, pues, que repentinamente todos los personajes del autor yucateco pueden convertirse en objetos, pero no para ser aniquilados o victimados. Leemos en Crónica de la intervención: "Fuiste un objeto, Anselmo era un objeto, Mariana sabía cómo ser un objeto y no quería más que ser un objeto. No quería nada. Ella ya no era 
ella. Un olvido innombrable. Nadie es el objeto de nadie. Los objetos ni siquiera son de sí mismos.” Esta situación se halla en el ámbito de la inocencia en el sentido anotado por Paz. Desde el momento en que no hay victimarios ni degradación o humillación, no hay culpables. Cuando surge la culpa, ésta es ambigua y se resuelve en la acción inocente de una transgresión en que la víctima es, en todo caso, el orden del trabajo, ya que es el principio de placer lo que prevalece. Los personajes de García Ponce no pertenecen a la nobleza ociosa: su trabajo -cuando se explicita- les sirve para obtener el placer.

Si en Lady Chatterley's lover la comunidad agrícola a la que se refieren Masters y Johnson es enaltecida como propicia para la sexualidad sana, es también cierto que aparece el adjetivo 'inocente' como un atributo de Connie, que el narrador alude a la belleza que envuelve el 'misterio fálico', dado que Connie se refiere al pene de Mellors como ‘inocente', que el rostro de éste -cuando se halla en una ocasión con Conniees comparado por el narrador con el de Buda: "motionless in physical abstraction”, y que el acto amoroso entre Connie y Mellors es calificado como un "acto creativo, mucho más que procreativo”, lo cual es ya una transgresión del orden religioso judeocristiano y del orden del trabajo.
Pero más interesante es la alusión a Abelardo y Eloísa: “¡El refinamiento de la pasión, las extravagancias de la sensualidad! Y necesaria, siempre necesaria para quemar las falsas vergüenzas y fundir el pesado mineral del cuerpo en la pureza. Con el fuego de la completa sensualidad.” A propósito de esta novela, el mismo Lawrence expresa en un ensayo su deseo de que los seres humanos puedan pensar el sexo limpiamente. Mientras que en Trópico de capricornio, Miller dice que su pene "presentaba un aspecto tan inocente como siempre”. La diferencia entre Lawrence, Miller y García Ponce radica en que el primero identifica -en sus ensayos- al sexo auténtico con la pasión por la fidelidad, contrapuesta a la prostitución, y asimismo propone al falo como el auténtico "puente hacia el futuro”, mientras que Miller alude al 'mundo ovárico'. No obstante, los tres proponen la inocencia del sexo.

Por el contrario, Sade, cuyos conceptos de virtud y de vicio están inscritos en la transvaloración racionalista de una moral, es ajeno a esa experiencia. Él no desune para unir. En el Marqués, como en SacherMasoch, hay relaciones desesperadas: la búsqueda del placer por el placer (por ser parte de lo natural) conlleva un dolor que suele desembocar en la anulación del otro, en la 
NOTAS

intolerancia, y no en la mutua aniquilación por medio del placer extático.

En Crónica..., María Inés expresa que "también esperaba que José Ignacio me matara, mejor dicho me mataba cada vez que hacíamos el amor, era, es, ese mismo deseo de desaparición, de que me aniquilaran por completo para ser en el otro, para ser el otro, no pertenecerle, sino ser él”, y agrega: “Ese deseo de aniquilación sólo es femenino. Al ser él, yo no voy a ser un hombre. Lo convierto en mujer": he ahí la continuidad a la que se refiere Bataille y que se experimenta en el erotismo de los cuerpos, concretamente en el orgasmo, en la petite mort. No pertenecer al otro, sino ser el otro implica la unión sustancial de una experiencia extática inexistente en el sádico, quien siempre es él mismo y reafirma su discontinuidad en su libertad de anular al otro.

A pesar de la evidente disponibilidad sexual de muchas mujeres, que obliga a representarlas y recrearlas con el poder de la vista, las obras de García Ponce no descansan en la simple pornografía, en la banal transgresión de las costumbres estereotipadas por el simple hecho de transgredirlas, en la frívola descripción de 'perversiones' o 'anormalidades' de la sexualidad. La voluntad del autor no reside en insultar a la sociedad. Va más allá. En sus perso- najes no hay malicia ni conciencia de que están haciendo mal o de que están transgrediendo normas, y en esto coincide con D. H. Lawrence, cuando, en un ensayo sobre Lady Chatterley's lover, afirma: "no merece la pena mantener el sucio deseo de épater le bourgeois, de desconcertar a la gente normal. Si utilizo palabras tabú, es por un motivo”. Ese motivo obedece a la necesidad de un vocabulario para representar lo que él considera como la armonía entre sexo y pensamiento en la vida: "Debemos aceptar la palabra culo del mismo modo que aceptamos la palabra cara, puesto que culos tenemos y tendremos siempre”, aclara.

La insistencia en la 'pureza' e 'inocencia’ de las protagonistas más importantes de las novelas de García Ponce es símbolo de su falta de culpa. Esto constituye una obsesión en el escritor. De Geneviève se dice: “Tan inocente, tan sensual. Era la pureza misma." Entonces estos personajes se mueven en lo que Nietzsche califica de 'extramoral', en cuanto a que el valor de sus acciones no reside específicamente en sus intenciones. De tal modo, reaparece la inocencia: "Más allá del bien y del mal está tu reino. Tu inocencia está en no saber lo que es inocencia”, afirma Nietzsche. Literalmente, en la superficie de sus acciones, hemos detectado la transgresión, pero también -en el caso de 
María Inés- la toma de conciencia $a$ posteriori de la unión extática con el otro. Lo interesante es que en la apariencia esto es precisamente lo no-intencionado, el valor decisivo de las acciones, según la psicología nietzscheana, para la que, finalmente "lo que se hace por amor acontece siempre más allá del bien y del mal.” 